\title{
A Study of Body Mass Index (BMI) of Nepalese Women Attending Gynaecology Clinic
}

\author{
Padhye SM ${ }^{1}$ \\ 'Department of Obstetrics and Gynaecology, Kathmandu Medical College Teaching Hospital, Kathmandu, Nepal.
}

\section{ABSTRACT}

This prospective study was carried out to find out the body mass index (BMI) of all the women attending a gynaecological clinic at Kathmandu Valley. Total of 1450 women attended this clinic over the study period. After excluding few hundreds of women, one thousand women of reproductive age (15-49) were enrolled.

Detail history was taken, general, systemic and pelvic examinations were performed and a provisional diagnosis was made on the clinical ground. In this process height and weight of each patient was measured then Body Mass Index (BMI) was calculated.

Eight percent $(8 \%)$ of women were underweight and equal numbers of them were obese too. Forty-four point six percent were healthy and 37.3 were overweight. Most of them were diagnosed vaginitis, urinary tract infection (UTI), pelvic inflammatory disease (PID), subfertility, menstrual disorders, and cervical conditions. In eleven percent no gynaecological abnormalities were detected (NAD). Commonly diagnosed conditions were vaginitis, UTI, PID, primary subfertility and menstrual distorders were the commonly diagnosed conditions.

Key words: Body Mass Index, Nepalese women, Overweight, Underweight.

\section{INTRODUCTION}

In many cities in Asia prevalence of overweight defined as Body Mass Index (BMI) more than $25 \mathrm{~kg} /$ metre square was higher than $23 \%$. This increase in the prevalence of overweight is probably associated with industrialisation and urbanisation, which result in changed eating habits and lifestyles.

In Nepal it is observed that due to more and more urbanisation and sedentary lifestyle nowadays, the women seem to be having overweight. Although the per capita income is only $\$ 311$ U.S. dollar, the gap between rich and poor is getting greater and this has influenced the society.

This Study was conducted at Kathmandu with a view to identify the prevalence of underweight, overweight and obesity among Nepalese women of reproductive age (15-49) attending a gynaecological clinic at Kathmandu District of Nepal. Body Mass Index (BMI) was defined as Weight in kilogram divided by square of height in metres (BMI = weight in kilogram/height in metres ${ }^{2}$ ). BMI: Underweight $=15-19.5$, Normal $=20-24.9$, overweight $=25-29.9$ and obese $=30$ and above. This study was carried out to find out the body mass index (BMI) of Nepalese women of reproductive age (RA) group (15-49 years) attending a gynaecological clinic at urban setting of Kathmandu.

\section{MATERIAL AND METHODS}

This is a prospective observational study conducted at Kathmandu for the period of December 2003 to July

\section{Correspondence:}

Prof. Dr. Saraswati M. Padhye

Department of Obstetrics and Gynaecology Kathmandu Medical College Teaching Hospital Sinamangal, Kathmandu, Nepal.

Email: saraswati.padhye@gmail.com 
2007. Total of 1450 women attended this clinic over the study period. Women below the age of 15 and above 49 , pregnant women, those who were on hormones or hormonal contraceptives were excluded from this study; remaining one thousand women of reproductive age attending gynaecological consultation office/clinic were enrolled. Their verbal consents were taken. Detail history of women registered for the consultation were taken as to why did they come to the clinic, and what were their main complaints. Menstrual, obstetrical, hormonal and contraceptive history was taken. Blood pressure was taken, general examination, systemic including pelvic examinations were done. A provisional diagnosis was made. If necessary a simple haematological test and vaginal discharge was sent for hanging drop method and results were noted in case of vaginitis. Their height in centimetres and weight in kilograms were measured, then Body mass index was calculated as BMI = weight in $\mathrm{kg} /$ height in meters, ${ }^{2}$

\section{RESULT}

Among 1000 women of reproductive age (15-49) with various complaints, Underweight 8, Healthy 44.6, Overweight 37.3 and Obese 10.1 per cent were found. Maximum number of patients were between the age 25-29 ( $n=223)$, maximum underweight $(n=21)$ and healthy ( $n=110$ ) were found in this age group. Overweight ( $n=88$ ), at 30 to 34 and obese ( $n o=33$ ) were maximum at $35-39$ years of age (Table 1). Average numbers of children were 2, out of 853.(Excluding 147 out of which there were unmarried 24; sub fertile 100 and amenorrhic 23). Eighty-one women had permanent sterilisation $(8.1 \%), 74$ women's spouse had vasectomised $(7.4 \%)$, 45 of them were using Copper T $(4.5 \%), 51$ of them were using Condom (5.1\%).Only 13 of them were using Hormonal contraception (1.3\%).
It was noted from Table 2 that as the age advances the $\mathrm{BMI}$ also seems to be rising. Among 1000 women the main gynaecology findings were veginitis, UTI, PID etc. infection was prevalent in $42.6 \%$ cases. $14.7 \%$ were having menstrual problem. $10 \%$ of cases presented with subfertility. $13.5 \%$ had come for check up and found to have no abnormalities detected(NAD). 16.1\% included Post op. check-up, fibroid, post coital bleeding, erosion, dysparaunea.

* Postoperative chec-up, fibroid, post coital bleeding, erosion such as Lukoplakia vulva, cyst in labia minora, uterine synaechaea, endometriosis, polycystic ovaries, dyspareunea, pre-op check up etc.

\section{DISCUSSION}

Though this study was carried out at urban setting, the clients had attended from various parts of the country, which has covered about 72/75 districts. The type of women was of middle to lower middle class of RA who could afford to pay the clinic fees.

Reproductive-aged women are subject to numerous stresses affecting their health and well-being. In the present study it was noted that vaginitis being common to all groups, Primary sub fertility, PID, dysmenorrhoea in underweight women; UTI, PID, subfertility, menstrual disturbances, breast problems and cervical conditions in healthy; UTI, PID, menstrual trouble, subfertility in overweight; and UTI, PID, menorrhagia and breastconditions were main problems among obese women. It has been noted that thewomen are getting heavier after the age of 30.Present study indicates that the childbearing tendency of Nepalese women also is affected that the average number of child was found to be 2 .

With age, the women are likely to limit their activities due to physical or mental/emotional problems. Regular,

Table 1. BMI according to the Age Group

\begin{tabular}{|c|c|c|c|c|c|}
\hline Age & No. of Patient & Underweigh & Healthy & Overweight & Obese \\
\hline $15-19$ & 20 & 5 & 12 & 3 & 0 \\
\hline $20-24$ & 133 & 20 & 83 & 28 & 2 \\
\hline $25-29$ & 233 & $21(9 *)$ & $110(49 *)$ & 72 & 20 \\
\hline $30-34$ & 221 & 16 & 100 & $88(40 *)$ & 17 \\
\hline $35-39$ & 178 & 10 & 63 & 72 & $33(19 *)$ \\
\hline $40-44$ & 151 & 6 & 55 & 71 & 19 \\
\hline $45-49$ & 74 & 2 & 23 & 39 & 10 \\
\hline Total & 1000 & $80(8 \%)$ & $446(44.6 \%)$ & $373(37.3 \%)$ & $101(10.1 \%)$ \\
\hline
\end{tabular}

*in Percent 
Padhye et al. A Study of Body Mass Index (BMI) of Nepalese Women Attending Gynaecology Clinic

moderate or vigorous physical activity can help to improve health and wellbeing. Lack of physical activity has been associated with many serious risk factors and health conditions such as overweight, obesity, leading to hypertension, heart disease, osteoporosis, diabetes and cancer. ${ }^{1}$ In a study conducted at Kolkata, ${ }^{2} 32.25 \%$ were overweight and $67.74 \%$ were obese. In their study $75.8 \%$ were primarily obese with menstrual irregularities, primary and secondary amenorrhoea, oligomenorrhoea and hypomenorrhoea. They had weight reduction

\begin{tabular}{|lcccr|}
\hline \multicolumn{5}{|c|}{ Table 2. Age specifice Height, Weight and BMI } \\
\hline Age & No. of Patient & Height & Weight & BMI \\
$15-19$ & 20 & 1.5 & 48.75 & 21.45 \\
$20-24$ & 133 & 1.51 & 50.39 & 22.21 \\
$25-29$ & 223 & 1.52 & 55.66 & 24.22 \\
$30-34$ & 221 & 1.53 & 57.33 & 24.52 \\
$35-39$ & 178 & 1.51 & 59.21 & 25.79 \\
$40-44$ & 151 & 1.51 & 58.4 & 25.53 \\
$45-49$ & 74 & 1.52 & 59.57 & 25.93 \\
Total & 1000 & & & \\
\hline \hline
\end{tabular}

programme too. In the discussion, they have mentioned that amenorrhoea, endometrial hyperplasia, endometrial adenocarcinoma, oligomenorrhoea, polycystic ovarian disease, elevated oestrogen and androgen and deranged $\mathrm{LH} / \mathrm{FSH}$ ratio were common in cases of obesity. The menstrual irregularities were improved after weight reduction. In the present study only $10 \%$ were obese with menstrual problems of $15 \%$. In a study done in Vietnam the age and sex standardized prevalence of overweight and obesity using Asian specific BMI cut off $23.0 \%$ and $27.5 \% \mathrm{~kg} / \mathrm{m}^{3}$ was $26.2 \%$ and $6.4 \%$ respectively. They found the prevalence of overweight and obesity slightly higher in females (33.6\%) than males $(31.6 \%)$ and progressively increased with age. Same trends were noted in the present study though the Asian specific BMI (which was 23.0 and $27.5 \mathrm{~kg} / \mathrm{m}^{2}$ ) was not implied. The adult population in HCMC Vietnam being

\begin{tabular}{|lcccc|}
\hline \multicolumn{5}{|c|}{ Table 4. Disease specific Height, Weight and BMI } \\
\hline $\begin{array}{l}\text { Diagnosis } \\
\text { Mesntrual }\end{array}$ & No. of Patients & Height & Weight & BMI \\
Problem & 147 & 1.51 & 57.44 & 55.07 \\
Infection & 426 & 1.52 & 56.28 & 24.44 \\
Subfertility & 100 & 1.51 & 53.41 & 23.57 \\
$\begin{array}{l}\text { Conditions } \\
\text { and Problem }\end{array}$ & 31 & 1.52 & 57.19 & 24.77 \\
$\begin{array}{l}\text { Check- } \\
\text { up/NAD }\end{array}$ & 135 & 1.52 & 57.6 & 24.99 \\
$\begin{array}{l}\text { Others } \\
\text { Total }\end{array}$ & 161 & 1.52 & 57.24 & 24.68 \\
\hline
\end{tabular}

in early "Nutrition transition", they have approximately equal prevalence of low and high BMI so are the findings of present study. ${ }^{3}$

In Nepal, "Anthropometric studies on students of Nepal Medical College were done. ${ }^{4}$ In the study, of the female students (who are of RA of course,) $38.6 \%$ and $2.2 \%$ of the 4 th batch and $36.6 \%$ and $4.9 \%$ of the $5^{\text {th }}$ batch were underweight and overweight respectively. And a significant degree of under nutrition (20\%) were revealed in 2 batches of female medical students. In the present study, there was $8 \%$ underweight and $37.3 \%$ of them were overweight in case of women of RA.

The 1993 WHO expert committee emphasised that weight gain in adult life is associated with increased morbidity and mortality at increasing BMls and that cutoff points for the amount of overweight should not be interpreted in isolation but in combination with other risk factors of morbidity and mortality. ${ }^{5}$ The WHO expert consultation on BMI in Asian population which met in Singapore from July 8-11 2002, focused exclusively on forth coming problems related to overweight and obesity.

Table 3. According to the Diagnosis

\begin{tabular}{|c|c|c|c|c|c|}
\hline Diagnosis & No. of Patients & Underweight & Healthy & Overweight & Obese \\
\hline Mesntrual Problem & 147 & 13 & 58 & 57 & 19 \\
\hline Infection & 426 & 39 & 197 & 146 & 44 \\
\hline Subfertility & 100 & 9 & 51 & 37 & 3 \\
\hline Conditions and Problem & 31 & 0 & 14 & 13 & 4 \\
\hline Check-up/NAD & 135 & 8 & 52 & 60 & 15 \\
\hline Others & 161 & 11 & 74 & 60 & 16 \\
\hline Total & 1000 & 80 & 446 & 373 & 101 \\
\hline
\end{tabular}


Therefore, we Nepalese should be aware in time and should start acting timely. Appropriate body mass index for Asian population and its implications for policy and intervention strategies have to be considered in future plans and programmes.

\section{CONCLUSION}

There is limited study data about BMI of reproductive age of women of Nepal. In the present study, underweight and obese being $8 \%, 10 \%$ the overweight of $37.3 \%$ and $44.6 \%$ of healthy (normal BMI) respectively, it indicates that the "Healthy" Nepalese women to be only $45 \%$. So far it is understood that this type of study was not being done previously in reproductive age group of women of Nepal, there is a lot of scope to do further researches along with interventions if possible to prevent the overweight/obesity in women of Nepal which may emerge many problems and complications.

\section{ACKNOWLEDGEMENT:}

To all the patients, Dr. Preeti Bhardwaj, Mr. Ranjit Thapa and Mrs Padma Shkya for their help during my research.

\section{REFERENCES}

1. Womens' Health U.S.A. Health Resources and Services Administration. U.S. Dept. of Health \& Human Services, 2007. http:// mchb.hrsa.gov/whusa_05/pages/0420oo.htm

2. Biswas A, Kundu MK, Kyal A. A study of menstrual irregularities in relation to obesity in terms of body mass index. Obs \& Gynae Today 2007 Jan;12(1):40-3.

3. Coung TQ, Dible MJ, Bowe S, Hanh TTM, Loan TTH. Obesity in adults: an emerging problem in urban areas of Ho Chi
Minh City, Vietnam. Eur J Clin Nutr 2007;61:673-681.

4. Kumar A, Ramiah S. Anthropometric studies on students of the Nepal Medical college : Elbow breadth. Kathmandu Univ Med J 2005;3(12):345-8.

5. WHO Expert Consultation. Appropriate body-mass index for Asian populations and its implications for policy and intervention strategies. Lancet 2004 Jan 10;363(9403):157-63. 